\title{
Inovações Gerenciais em Evidência: Uma Análise baseada na Percepção de Gestores
}

\author{
Managerial Innovations in Evidence: An Analysis Based on the Perception of Managers
}

\author{
Ana Paula Moreno Pinho' \\ Mara Rosalia Ribeiro Silva ${ }^{2}$ \\ Marina Freire de Paiva Ramos Souza ${ }^{3}$ \\ Jose Carlos Lazaro ${ }^{4}$
}

\begin{abstract}
Resumo
O objetivo geral deste artigo é analisar a percepção dos gestores sobre o fenômeno da inovação gerencial em uma empresa cimenteira no Brasil. Utilizou-se o modelo de sistemas abertos de Quinn (2003), cujas competências gerenciais estão relacionadas a concepções de poder, negociação, novas ideias, mudança organizacional e criatividade. Esta pesquisa qualitativa foi realizada por meio de entrevistas semiestruturadas, orientadas por tiras de papeis, que contribuíram para promover dinamicidade durante a coleta de dados. A análise foi feita por meio da análise de conteúdo e a codificação das informações foi realizada pelo software de pesquisa qualitativa ATLAS.ti 7. A partir da análise, percebeu-se que a apresentação e o compartilhamento de novas ideias são considerados por eles como principais elementos relacionados ao fenômeno da inovação gerencial. Além disso, os gestores perceberam que a estrutura organizacional proporciona condições para um desempenho gerencial inovador, contribuindo para o processo de implementação de inovações gerenciais.
\end{abstract}

Palavras-chave: inovações gerenciais; competências gerenciais; gestão organizacional.

\section{Abstract}

The article aims to analyse the managers' perception of the managerial innovation phenomenon in a cement company in Brazil. Quinn's (2003) open systems model was used, whose managerial competencies are related to conceptions of power, negotiation, new ideas, organizational change, and creativity. This qualitative research was carried out through semi-structured interviews, guided by paper strips, which contributed to promoting dynamism during data collection. The analysis occurred through content analysis, and the information coding was performed by the qualitative research software ATLAS.ti 7. From the analysis, it was realized that the presentation and sharing of new ideas are considered by them as the main elements related to the phenomenon of managerial innovation. Besides, managers realized that the organizational structure provides conditions for innovative managerial performance, contributing to the implementing managerial innovations process.

Keywords: managerial innovations; managerial competencies; organizational management.

Professora Adjunto da Universidade Federal do Ceará, no Programa de Pós Graduação em Administração e Controladoria (PPAC) e desenvolve pesquisas relacionadas aos temas do Comportamento Organizacional, da Gestão de Pessoas e Inovação Gerencial.

Mestrado em Administração e Controladoria pela Universidade Federal do Ceará. Desenvolveu pesquisas nas áreas de Economia Circular, Modelo de Negócios Sustentáveis no Laboratório de Estudos em Competitividade e Sustentabilidade (LECoS). 


\section{INTRODUÇÃO}

Embora tradicionalmente as pesquisas em inovação tenham priorizado a perspectiva tecnológica desse fenômeno, principalmente com foco em produtos e processos de fabricação, as investigações em inovações não tecnológicas têm sido gradualmente mais frequentes à medidade que se reconhecem seus benefícios e impactos na competitividade entre organizações e entre países (VOLBERDA; VAN DEN BOSCH; HEIJ, 2013). Inovações não tecnológicas propõem criações radicais ou incrementais capazes de agregar valor à organização, mas que não são diretamente baseadas ou facilitadas pela tecnologia para fins comerciais (ČERNE; KAŠE; ŠKERLAVAJ, 2016).

Nesse contexto, as inovações gerenciais emergiram como inovações não tecnológicas que possuem impacto direto na performance das empresas e que, segundo Birkinshaw, Hamel e Mol (2008), incidem em questões organizacionais ligadas à produtividade, rentabilidade, eficiência e eficácia dos processos, à sustentabilidade do negócio e à vantagem competitiva. A concepção de inovação, no âmbito gerencial, está diretamente associada a novas maneiras de coordenar, avaliar e planejar o conjunto de recursos humanos, financeiros e materiais de uma empresa (CHANDLER, 1997), no intuito de buscar novas formas de organização e operação dos negócios (NICKELL; NICOLITSAS; PATTERSON, 2001).

Baseado nesse entendimento, o conceito de inovação gerencial, embora difuso na literatura (DAMANPOUR; ARAVIND, 2011), tem como ideia principal a criação e implementação de novas abordagens para realizar o trabalho da gestão (DAMANPOUR, 2014), que resultam em melhorias na eficiência operacional e desempenho organizacional (LIN; SU, 2014). Em complemento, as inovações gerenciais podem ser direcionadas para três principais focos de mudança: atividades e práticas gerenciais, processos gerenciais e estruturas organizacionais (LOPES, 2017).

O papel dos gestores para o sucesso das inovações gerenciais está em idealizar, executar e acompanhar novas práticas de gestão que orientam a organização na obtenção dos seus objetivos. Assim, gestores são constantemente desafiados a desenvolver e direcionar suas competências, de forma a permitir a obtenção, o compartilhamento e a retenção de novas ideias, colaborando, consequentemente, para a criação de um ambiente interno propício para a geração de inovações. As competências gerenciais representam elementoschave no processo de viabilização das inovações gerenciais, já que, segundo Carbone, Brandão e Leite (2008), significam o conjunto de conhecimentos, habilidades e atitudes relacionadas à performance dos gestores, os quais atuam como agentes de inovação nas empresas.

Em se tratando de inovações, a indústria cimenteira representa um caso peculiar. Por um lado, essa indústria possui como produto o cimento, o qual é considerado uma commodity, pois, de acordo com Haguenauer (1997), possui baixa diferenciação entre outros produtos semelhantes no mercado e tem uma regulamentação restrita sobre suas especificações técnicas quanto à resistência e estabilidade. Essas características resultam em um produto que pouco inova na sua apresentação(em forma de pó) e aplicação específica (como aglutinador em obras de infraestrutura).

Por outro lado, a indústria cimenteira, para se manter competitiva, além de acompanhar as demandas da cadeia de suprimentos do setor de construção civil (FREJ; ALENCAR, 2010) e de sustentabilidade, tem desenvolvido inovações em diferentes aspectos. Primeiramente, o processo de fabricação do cimento tem tido um viés sustentável, buscando a substituição de combustíveis e matérias-primas por fontes alternativas, contribuindo com a redução da emissão de dióxido de carbono $\left(\mathrm{CO}^{2}\right)$. Portanto, existe um esforço de inovação na produção de cimento no sentido de melhorar, principalmente, a eficiência energética e utilizar combustíveis alternativos (BATTAGIN, 2010). O setor de logística sofreu alterações substanciais no intuito de dar vazão ao cimento, que é um dos insumos básicos para o desenvolvimento da infraestrutura, chegando em obras de construção de estradas, pontes, sistemas de abastecimento de água, tratamento de esgoto, escolas, hospitais e habitação (AIRES et al., 2016).

Ao identificar essa dicotomia no perfil inovador da indústria do cimento, infere-se que as inovações que movem as operações industriais e que transformam um produto commodity em uma mercadoria, que envolve processos complexos de produção e logística, estão diretamente relacionadas a mudanças que ocorrem no campo gerencial.

Segundo últimos dados disponívies do Sindicato Nacional das Indústrias de Cimento (SNIC, 2014), o nível de produção colocou o Brasil no patamar de $5^{\circ}$ maior produtor de cimento do mundo, superado por China, Índia, Estados Unidos e Irã. Os principais consumidores dessa indústria, no Brasil, são os revendedores varejistas do ramo de materiais de construção, os quais são intermediários na cadeia entre a indústria e os consumidores individuais (MEDEIROS; LEVY, 2015).

Diante da singularidade do perfil inovador da indústria cimenteira e da relevância brasileira na produção do cimento em escala mundial, o objetivo deste artigo é analisar a percepção de gestores sobre o fenômeno da inovação gerencial em uma empresa da indústria cimenteira no Brasil.

Como principais contribuições, este artigo busca preencher uma lacuna na literatura acerca das inovações gerenciais, sendo estas analisadas sob a perspectiva da implementação de práticas inovadoras de gestão e o seu relacionamento com o desenvolvimento de competências gerenciais. Ademais, tendo em vista que o setor cimenteiro é um segmento que possui baixo nível de inovação no produto final, esta pesquisa pretende ampliar a discussão sobre as possibilidades de inovação que têm se desenvolvido nos níveis gerenciais de uma empresa líder de mercado no ramo de cimento. 


\section{INOVAÇÕES GERENCIAIS}

A inovação é um fenômeno que pode ser analisado sob diversos níveis: individual, grupal, organizacional, industrial, entre outros (DAMANPOUR; ARAVIND, 2011). Ressalta-se que inovação é um conceito que emergiu no início do século XX (SCHUMPETER, 1911) e, embora sua discussão inicial tenha focado em desenvolvimento econômico, o próprio Schumpeter (1911) expõe que a inovação (novos fatores produtivos) pode ser tanto voltada para novos produtos quanto para processos de produção, novos mercados e novas maneiras de se organizar. Ao institucionalizar esse conceito amplo de inovação, a Organização para a Cooperação e Desenvolvimento Econômico (OCDE) definiu o que se encontra em seu Manual de Oslo: "Uma inovação é a implementação de um produto (bem ou serviço) novo ou significativamente melhorado, ou um processo, ou um novo método de marketing, ou um novo método organizacional nas práticas de negócios, na organização do local de trabalho ou nas relações externas" (OCDE, 2005, p.55).

Com essa amplitude conceitual, tanto a inovação ganha uma gama de possibilidades de temas a estudar (FAGERBERG; MOWERY; NELSON, 2006) quanto apresenta amplo processo de gestão (DODGSON; GANN; PHILLIPS, 2015). Assim, o estudo da inovação não é algo apenas macroeconômico, mas também organizacional, conforme vem sendo estudado por diferentes autores nas ultimas décadas (CHESBROUGH, 2003; CHRISTENSEN, 1997; DAVILA; EPSTEIN; SHELTON, 2007; TIDD; BESSANT; PAVITT, 2008).

Sob o escopo da abordagem organizacional da inovação, encontram-se as inovações gerenciais, as quais têm sido discutidas na literatura por meio de diversas nomenclaturas, como: inovação administrativa, organizacional e empresarial (DAMANPOUR, 2014). Essa diversidade de nomeclaturas se explica pela divisão de correntes de abordagem sobre o tema (DAMANPOUR, 2014). Para Kimberly (1981), existem duas linhas de abordagem sobre a inovação gerencial: uma que parte da ideia de que inovação é um processo, e outra que entende que inovação é um produto discreto ou um programa. Alguns anos depois e com mais campo de pesquisa, Lam (2006) identificou três correntes de pesquisa sobre inovação organizacional: uma focada na ligação entre forma estrutural e propensão de uma organização à inovação, derivando das teorias de desenho organizacional; a segunda focada no micro nível do processo da organização de desenvolver ideias para questões emergentes, derivada das teorias de cognição organizacional; e a terceira corrente de pesquisa, focada na mudança e adaptação organizacional e no processo por trás da criação de uma nova forma organizacional.

Para fins deste artigo, foi utilizada a segunda corrente (que dá ênfase ao nível micro do processo da organização). Embora seja considerado que as inovações gerenciais representam o desenvolvimento e implementação de novas atividades e práticas gerenciais, estratégias e estruturas organizacionais e processos gerenciais, que resultam em melhor desempenho organizacional (VACCARO et al., 2012; LOPES, 2017), neste artigo são analisados os novos processos organizacionais da indústria cimenteira em estudo e a ligação desses processos com as competências gerenciais.

Assumindo a segunda corrente deve-se, ainda, considerar que diferentes autores têm desenvolvido o conceito de inovações gerenciais na literatura ao longo dos últimos anos. Hamel (2006) descreve o fenômeno como a adoção de práticas gerenciais que fogem dos princípios, processos e práticas tradicionais existentes naquela organização. De forma semelhante, Birkinshaw, Hamel e Mol (2008) consideram tais inovações como a introdução de práticas, processos e estruturas gerenciais aplicadas em função dos objetivos organizacionais.

Vaccaro et al. (2012), por sua vez, explicam que inovações gerenciais são quaisquer novos processos, práticas e estruturas capazes de modificar o trabalho dos gestores na organização. Para Damanpour (2014), essas inovações significam o desenvolvimento de novas abordagens de execução da atividade gerencial, novas estratégias e estruturas organizacionais e novos caminhos para produzir mudanças nos procedimentos e no sistema administrativo.

Lin e Su (2014) definem que inovações gerenciais constituem a introdução e implementação de práticas, estruturas, técnicas e processos novos para certo contexto gerencial visando à eficiência organizacional. Em suma, as inovações gerenciais ocorrem no âmbito organizacional e possuem ênfase em três principais pilares: atividades e práticas gerenciais, processos gerenciais e estruturas organizacionais (LOPES, 2017). Esses pilares podem ser bem identificados na pesquisa de Khosravi, Newton e Rezvani (2019).

Conforme propõem Cunha Palma e Santos (2008), as inovações gerenciais são concretizadas por meio de um conjunto de decisões tomadas pelas organizações com o fim de conduzir todas as pessoas e departamentos ao alcance dos objetivos organizacionais estratégicos. Essa definição se alinha com a abordagem proposta por Elenkov, Judge e Wright (2005), Vaccaro et al. (2012) e Douglas, Overstreet e Hazen (2016). Destaca-se, nessa relação, o papel das competências atribuídas aos gestores no exercício das inovações gerenciais, assunto que será o tema da seção a seguir.

\section{COMPETÊNCIAS GERENCIAIS}

A inovação é um fenômeno que possibilita a competitividade, exigindo dos profissionais o desenvolvimento e a implementação de competências gerenciais para promover inovações, de forma que a organização obtenha resultados positivos e diferenciados no mercado em que atua. Assim, a implementação de inovações gerenciais está relacionada ao desenvolvimento de competências gerenciais. Segundo Carbone, Brandão e Leite (2008), competências significam um conjunto de conhecimentos, habilidades e atitudes que fazem parte do desempenho individual e que 
estão consoantes às estratégias organizacionais. As competências gerenciais são desenvolvidas para amparar as tomadas de decisão da gerência na condução das atividades organizacionais.

Nesse contexto, Quinn et al. (2003) propõem um modelo organizacional que abrange diferentes dimensões de modelos gerenciais com os respectivos papéis desempenhados pelos gestores na dinâmica organizacional, sendo que cada papel possui algumas competências gerenciais relacionadas, como mostra o Quadro 1. Para os autores, as competências gerenciais são aperfeiçoadas à medida que o indivíduo põe seu corpo de conhecimentos teóricos em prática, exercitando sua capacidade comportamental para cada situação no exercício de suas funções organizacionais.

Quadro 1 - Modelo de gestão organizacional e competências gerenciais.

\begin{tabular}{|c|c|c|}
\hline MODELO GERENCIAL & PAPEL DO GESTOR & COMPETÊNCIAS GERENCIAIS \\
\hline \multirow{6}{*}{ Modelo das relações humanas } & \multirow{3}{*}{ Papel de mentor } & 1. Compreensão de si mesmo e dos outros. \\
\hline & & 2. Comunicação eficaz. \\
\hline & & 3. Desenvolvimento dos empregados. \\
\hline & \multirow{3}{*}{ Papel de facilitador } & 1. Construção de equipes. \\
\hline & & 2. Uso do processo decisório. \\
\hline & & 3. Administração de conflitos. \\
\hline \multirow{6}{*}{ Modelo de processos internos } & \multirow{3}{*}{ Papel de monitor } & 1. Monitoramento do desempenho individual. \\
\hline & & 2. Gerenciamento do desempenho e processos coletivos. \\
\hline & & 3. Análise de informações com pensamento crítico. \\
\hline & \multirow{3}{*}{ Papel de coordenador } & 1. Gerenciamento de projetos. \\
\hline & & 2. Planejamento do trabalho. \\
\hline & & 3. Gerenciamento multidisciplinar. \\
\hline \multirow{6}{*}{ Modelo das metas racionais } & \multirow{3}{*}{ Papel de diretor } & 1. Desenvolvimento e comunicação de uma visão. \\
\hline & & 2. Estabelecimento de metas e objetivos. \\
\hline & & 3. Planejamento e organização. \\
\hline & \multirow{3}{*}{ Papel de produtor } & 1. Trabalho produtivo. \\
\hline & & 2. Fomento de um ambiente de trabalho produtivo. \\
\hline & & 3. Gerenciamento do tempo e do estresse. \\
\hline \multirow{6}{*}{ Modelo dos sistemas abertos } & \multirow{3}{*}{ Papel de negociador } & 1. Construção e manutenção de uma base de poder. \\
\hline & & 2. Negociação de acordos e compromissos. \\
\hline & & 3. Apresentação de ideias. \\
\hline & \multirow{3}{*}{ Papel de inovador } & 1. Convívio com a mudança. \\
\hline & & 2. Pensamento criativo. \\
\hline & & 3. Gerenciamento da mudança. \\
\hline
\end{tabular}

Fonte: adaptado de Quinn et al. (2003).

O modelo das metas racionais representa a busca de resultados produtivos por meio da eficácia organizacional, produtividade e lucro. Sob a ótica desse modelo, o gestor pode desempenhar os papéis de diretor e produtor. Ao diretor cabe o papel de deixar processos os organizacionais mais claros por meio de definição de objetivos e metas, planejamento e divisão de tarefas, além do estabelecimento de regras e políticas de conduta interna. As competências esperadas para quem desempenha esse papel são o desenvolvimento e a comunicação de uma visão, o estabelecimento de metas e objetivos, e planejamento e organização. O papel de produtor, por sua vez, é orientado para a tarefa, automotivado e persuasivo em envolver toda a equipe em prol da tarefa a ser cumprida, aumentando a produção e alcançando resultados satisfatórios. Espera-se que os produtores desenvolvam as seguintes competências: trabalho produtivo, fomento de um ambiente de trabalho produtivo e gerenciamento do tempo e do estresse.

O modelo dos processos internos é representado pela burocracia profissional, a qual representa um complemento do modelo das metas racionais, pois também enfatiza a eficácia organizacional. No entanto o foco é a continuidade e a estabilidade por meio da rotinização das atividades organizacionais, que envolvem processos como: definição de responsabilidades, manutenção de registros e definição de sistemas de controle e hierarquia. Nesse modelo encontram-se os papéis de monitor e coordenador. Quanto ao monitor, este desempenha a tarefa de supervisionar o trabalho e atuar como um analista, garantindo que as atividades estão sendo detalhadamente executadas e as regras cumpridas. Algumas competências que o monitor precisa desenvolver são: monitoramento do desempenho individual, gerenciamento do desempenho e processos coletivos, assim como análise de informações com pensamento crítico. O papel do coordenador é o de dar suporte à estrutura organizacional vigente e permitir o fluxo das ações 
nessa estrutura, envolvendo ações como: harmonizar o trabalho em equipe, enfrentar crises e solucionar problemas nos âmbitos tecnológico, logístico e doméstico. Espera-se que o coordenador desenvolva as competências de gerenciamento de projetos, planejamento do trabalho e gerenciamento multidisciplinar.

O modelo das relações humanas propõe como foco principal os valores referentes à participação da equipe, resolução de conflitos internos e construção de consenso, baseados no compromisso e em fatores motivacionais. Nesse modelo, sobressaem-se os papéis de mentor e facilitador. O mentor desempenha o papel do interesse humano, buscando ser solícito, atencioso, sensível, justo, procurando agregar equipes e solucionar conflitos. Nesse caso, espera-se que as competências desenvolvidas sejam: compreensão de si mesmo e dos outros, comunicação eficaz e desenvolvimento dos empregados. O facilitador é orientado para processos, canalizando esforços para a solução de conflitos interpessoais, entrosamento e colaboração das equipes de trabalho e reforço da moral do grupo. As competências relacionadas a esse perfil são: construção de equipes, uso do processo decisório e administração de conflitos.

O modelo dos sistemas abertos tem como premissa básica a busca da eficácia organizacional por meio da adaptabilidade e do apoio externo. Esse tipo de sistema está aberto para constantes adaptações, promovendo a aquisição e a manutenção dos recursos adquiridos no meio externo. Nesse contexto estão os papéis de negociador e inovador. O negociador desempenha o papel de representar sua unidade de negócios na construção de relacionamentos e parcerias com entes externos. Como competências, os negociadores devem desenvolver capacidades de construção e manutenção de uma base de poder, negociação de acordos e compromissos, e apresentação de ideias. Já o papel de inovador envolve o esforço de empreender, facilitando e construindo pontes para transformações e mudanças organizacionais. Como competências, os inovadores podem desenvolver: convívio com a mudança, pensamento criativo e gerenciamento da mudança.

Para fins deste artigo, será utilizado como base de análise o modelo dos sistemas abertos, cujas competências gerenciais estão relacionadas às concepções de poder, negociação, novas ideias, mudança organizacional e criatividade. Por se tratar de uma investigação com foco em inovações gerenciais, pressupõe-se que as competências desenvolvidas para uma gestão inovadora sejam aprimoradas no fluxo de conhecimentos que cruzam os ambientes internos e externos às organizações, sendo atribuído ao gestor o aperfeiçoamento dos papeis de negociador e inovador no objetivo de atingir os objetivos organizacionais.

\section{4. $\quad$ AMBIENTE INTERNO ORIENTADO PARA INOVAÇÃO}

A inovação é resultado dos processos de aprendizagem que as organizações vivenciam no seu ambiente interno, no qual é possível gerar e aplicar novos conhecimentos nas rotinas, processos e procedimentos organizacionais (ISIDRO FILHO; GUIMARÃES, 2010), resultando em ideias que representam soluções de problemas enfrentados nas empresas. É nesse sentido dinâmico e contínuo da inovação que se faz necessário que as políticas e práticas de gestão sejam orientadas para a permissão da criação e implementação de inovações.

A discussão sobre a influência dos ambientes interno e externo na geração de inovação tem motivado a realização de diferentes estudos no Brasil. Entre os principais resultados, destaca-se a presença de alguns elementos essenciais no ambiente interno como facilitadores de inovações, tais como: flexibilidade na gestão associada à gestão de pessoas e ao permanente investimento em tecnologias (CASTRO; BASQUES, 2006); desenvolvimento de cidadania organizacional (LEITE; DUTRA; ANTUNES, 2006); investimento em pesquisa e desenvolvimento, estrutura organizacional e estilo gerencial (COUTINHO; BOMTEMPO, 2007); comunicação antiburocrática, integração funcional entre as diversas áreas da empresa, encorajamento por parte da alta administração ao enfrentamento de desafios e um processo decisório participativo (MIGUEL; TEIXEIRA, 2009; VICK; NAGANO; SANTOS, 2009; PAROLIN; ALBUQUERQUE, 2010; VICENTI; MACHADO, 2010).

Fiates, Fiates, Serra e Ferreira (2010) consideram quatro variáveis fundamentais para garantir um ambiente propício à inovação. A primeira variável estudada é a cultura organizacional, a qual, quando orientada para a inovação, é direcionada à aquisição e compartilhamento de conhecimento entre trabalhadores, à vivência de novas experiências, à aceitação de riscos calculados e à possibilidade de aprender com os erros (NEELY; HII, 1998; SLUIS, 2004). A segunda variável é a estrutura organizacional, cuja principal característica para permitir inovações é a flexibilidade, facilitando respostas rápidas às mudanças no ambiente externo e na comunicação no ambiente interno. Os recursos humanos são considerados a terceira variável do ambiente interno orientado para inovação, pois o desenvolvimento de pessoas e de suas competências criativas colaboram diretamente com a qualidade das propostas de solução de problemas da organização. A quarta variável é a infraestrutura existente na organização, que permite a aquisição de informações e a sua transformação em conhecimento, envolvendo interação harmoniosa entre equipamentos tecnológicos e trabalhadores, favorecendo um fluxo contínuo de novas ideias.

Entre os estudos de referência sobre o ambiente interno orientado para inovação, salientam-se os construtos apresentados por Van de Ven, Angle e Poole (2000), os quais consideram que a inovação pode ser vista como um processo de desenvolvimento e implantação de uma novidade. Os autores elaboraram o modelo do Minnesota Innovation Research Program (MIRP), baseado em cinco conceitos: ideias, pessoas, transações, contexto e resultados. Esses conceitos se articulam no sentido de que a inovação é um processo motivado e coordenado por pessoas na busca 
por desenvolver e implementar ideias mediante diferentes transações de conhecimentos no contexto organizacional, a fim de chegar aos resultados desejados e pré-estabelecidos pelo corpo gestor. Na prática, para Van de Ven, Angle e Poole (2000), a inovação é um processo que não pode ser realizado individualmente, mas depende de um conjunto de variáveis que atuam em conjunto para atingir resultados, além de aceitação e legitimidade na organização.

Em suma, os diferentes estudos sobre o ambiente interno orientado para a inovação indicam que ocorre quando uma série de fatores colaboram para a movimentação de novas ideias dentro da organização. Esse movimento, segundo Lopes (2017), pode representar tanto o incentivo quanto o resultado de mudanças estruturais, nas práticas de gestão e nos processos gerenciais, que representam os pilares das inovações gerenciais.

\section{METODOLOGIA}

A profundidade da análise necessária para alcançar os objetivos traçados para esta pesquisa, que busca investigar a concepção do fenômeno da inovação gerencial do grupo escolhido, justifica a adoção da abordagem qualitativa. Pesquisas qualitativas possuem caráter analítico e reflexivo sobre as percepções proporcionadas por parte dos sujeitos agentes do fenômeno estudado, bem como promovem melhor compreensão a respeito das interações sociais que ocorrem em grupos e organizações, preocupando-se com o processo de aquisição dos resultados e o significado destes, sem a pretensão de mensurar fenômenos (GRAY, 2012; MARTINS; THEÓPHILO, 2009). Ademais, quanto aos objetivos, esta pesquisa se caracteriza como exploratória, por se tratar de uma investigação que tem como objetivo central desenvolver e esclarecer idéias até então não profundamente investigadas, no intuito de formular problemas para estudos posteriores (GIL, 2010). Quanto aos procedimentos técnicos para a coleta de dados da pesquisa, foi realizada um estudo de campo com entrevistas semiestruturadas. O estudo de campo ocorre quando o pesquisador se desloca para o local onde os sujeitos da pesquisa estão, na busca por aprofundar uma realidade específica, observar diretamente o fenômeno investigado e captar relatos e impressões sobre aquela realidade (GIL, 2010). No estudo de campo, julgou-se pertinente a realização de entrevistas semiestruturadas, as quais representam questionamentos básicos que são apoiados na literatura de base e que estão relacionados ao tema da pesquisa, dando a oportunidade para que outras perguntas venham a surgir de acordo com o desenrolar da entrevista (TRIVIÑOS, 1987).

A respeito das entrevistas, por questão de conveniência, foram entrevistados dez gestores de uma empresa da indústria cimenteira sediada no Nordeste do Brasil. O grupo de participantes é composto por dez gestores, de acordo com a descrição apresentada no Quadro 2, a seguir:

Quadro 2 - Descrição dos sujeitos da pesquisa.

\begin{tabular}{|c|c|c|l|l|}
\hline ENTREVISTADO & IDADE & SEXO & \multicolumn{1}{|c|}{ TEMPO DE SERVIÇO NA ORGANIZAÇÃO } & \multicolumn{1}{|c|}{ CARGO } \\
\hline E1 & 41 & $\mathrm{~F}$ & 8 meses & Coordenadora contábil \\
\hline E2 & 38 & $\mathrm{M}$ & 5 meses & Gestor comercial \\
\hline E3 & 58 & $\mathrm{M}$ & 8 anos & Supervisor de departamento pessoal \\
\hline E4 & 27 & $\mathrm{~F}$ & 6 anos & Supervisora comercial \\
\hline E5 & 31 & $\mathrm{M}$ & 3 anos & Analista de recursos humanos \\
\hline E6 & 50 & $\mathrm{~F}$ & 4 anos e 6 meses & Coordenadora de recursos humanos \\
\hline E7 & 60 & $\mathrm{M}$ & 3 anos & Supervisor de produção \\
\hline E8 & 32 & $\mathrm{M}$ & 2 anos e 6 meses & Supervisor de manutenção elétrica \\
\hline E9 & 46 & $\mathrm{M}$ & 4 anos e 6 meses & Supervisor de manutenção civil \\
\hline E10 & 35 & $\mathrm{~F}$ & 4 meses & Supervisora de produto e assessoria técnica \\
\hline
\end{tabular}

Fonte: Elaborado pelos autores (2021).

As entrevistas foram marcadas e realizadas de forma individual, de acordo com a disponibilidade dos participantes e ocorridas no ambiente de trabalho de cada um deles. Cada entrevista durou, em média, 17 minutos. Foi solicitada aos participantes a permissão de gravação das entrevistas concedidas para transcrições literais e análises posteriores. Com a autorização, as entrevistas foram gravadas por meio de aparelho smartphone. O roteiro de entrevistas foi dividido em quatro etapas, sendo a primeira para coletar dados demográficos dos participantes e três outras seções para atender aos três objetivos específicos do artigo, como demonstra o Quadro 3. 
Quadro 3 - Etapas da entrevista e suas respectivas partes.

\begin{tabular}{|c|c|c|c|}
\hline $\begin{array}{l}\text { ETAPA 1 } \\
\text { Identificação dos dados } \\
\text { demográficos } \\
\\
\text { 1. Questionamento sobre } \\
\text { dados pessoais: sexo, idade, } \\
\text { escolaridade, estado civil, } \\
\text { profissão, ocupação, tempo } \\
\text { de serviço no cargo e na } \\
\text { organização. }\end{array}$ & $\begin{array}{l}\text { ETAPA } 2 \\
\begin{array}{l}\text { Identificação da concepção } \\
\text { de inovação gerencial }\end{array} \\
\text { 1. Questionamento sobre o } \\
\text { significado de inovação e } \\
\text { inovação gerencial. } \\
\text { 2. Entrega de } 5 \text { papéis em } \\
\text { branco para escrita de } 5 \\
\text { práticas gerenciais exercidas } \\
\text { na sua atuação como } \\
\text { gestores. } \\
\text { 3. Escolha da prática mais } \\
\text { inovadora entre as } 5 \text { práticas } \\
\text { escritas por eles. }\end{array}$ & $\begin{array}{l}\text { ETAPA 3 } \\
\text { Identificar as cognições das } \\
\text { competências gerenciais } \\
\text { 1. Apresentação de } 5 \\
\text { fichas (poder, negociação, } \\
\text { novas ideias, mudança } \\
\text { organizacional, criatividade), } \\
\text { questionando a concepção dos } \\
\text { gestores sobre as palavras } \\
\text { e sua percepção sobre tais } \\
\text { aspectos na empresa. } \\
\text { 2. Solicitação para colocar } \\
\text { as } 5 \text { fichas em ordem de } \\
\text { importância tendo em vista as } \\
\text { práticas gerenciais inovadoras. }\end{array}$ & $\begin{array}{l}\text { ETAPA } 4 \\
\text { Identificação da percepção sobre o } \\
\text { ambiente interno orientado para inovação } \\
\\
\text { 1. Questionamento sobre os tipos } \\
\text { de inovação gerencial identificados } \\
\text { na empresa, quais tipos de barreiras } \\
\text { encontradas para inovar e sobre o } \\
\text { incentivo do gestor. }\end{array}$ \\
\hline
\end{tabular}

Fonte: Elaborado pelos autores (2021).

A primeira etapa da entrevista teve início com perguntas relacionadas aos dados pessoais dos entrevistados, os quais responderam aos seguintes itens: sexo, idade, escolaridade, estado civil, profissão, ocupação, tempo de serviço no cargo e na organização.

A segunda etapa teve o intuito de identificar a concepção de inovação gerencial sob a ótica dos gestores. Para atingir esse objetivo, essa fase foi dividida em três partes. Em primeiro lugar, foram feitas as perguntas "o que vem à sua mente quando você pensa na palavra inovação?" e "o que vem à sua mente quando você pensa em práticas gerenciais inovadoras?". Dando continuidade, foram entregues cinco papéis em branco e canetas para que eles pudessem escrever cinco práticas gerenciais que exerciam na sua atuação como gestores. Por último, após a escrita das cinco práticas, foi perguntado qual (ou quais) daquelas práticas os gestores consideravam inovadoras na sua ação gerencial e porquê. A terceira etapa da entrevista teve como objetivo identificar as cognições dos gestores acerca das competências gerenciais e fazer uma relação com a sua ação gerencial. Para tanto, foi utilizado o procedimento metodológico aplicado por Pinho (2009) e publicado posteriormente por Pinho, Bastos e Rowe (2015). Seguindo a ideia de Pinho (2009), e com o objetivo de guiar os entrevistadores nessa fase da entrevista, foram elaboradas cinco fichas contendo palavras que representam as competências gerenciais presentes no modelo de sistemas abertos de Quinn et al. (2003): poder, negociação, novas ideias, mudança organizacional e criatividade. As fichas foram exibidas uma a uma para os gestores e, à medida que as fichas iam sendo expostas, foi questionado qual a concepção dos gestores sobre as palavras nelas contidas. A seguir, foi solicitado aos entrevistados que colocassem as fichas em ordem de importância para o contexto das práticas gerenciais inovadoras na organização de acordo com seus próprios critérios.

A quarta e última etapa da entrevista teve o propósito de identificar a percepção dos gestores sobre o ambiente interno orientado para inovação. Esse objetivo específico foi investigado por meio das perguntas "quais as formas de inovação gerencial na organização e como são implementadas?", "quais os tipos de barreira que são encontrados para inovar?" e "seu gestor incentiva o processo de inovação gerencial na organização?"

A análise dos dados foi feita por meio da análise de conteúdo, segundo Bardin (2011), que busca identificar e compreender, de maneira sistemática, diferentes significados e significantes, além de temas e procedimentos inseridos nos textos. A avaliação do material empírico coletado, segundo esse método, seguiu o rigor de três etapas. Primeiramente, houve a pré-análise, momento em que foi feita a sistematização das informações gerais. A segunda etapa foi a exploração do material, momento em que foi realizada a codificação, classificação e a categorização do conteúdo, com o auxílio do software ATLAS.ti versão 7.0. A última etapa da análise de conteúdo foi o tratamento, inferência e interpretação das informações, tendo como produto a análise crítica e reflexiva do material coletado, descrito na seção a seguir. 


\section{RESULTADOS E DISCUSSÃO}

Na primeira categoria de análise foram consultadas as concepções dos gestores a respeito de inovação, assim como de práticas gerenciais inovadoras, gerando a rede semântica representada pela Figura 1.

Figura 1 - Dimensão da concepção sobe inovação gerencial.

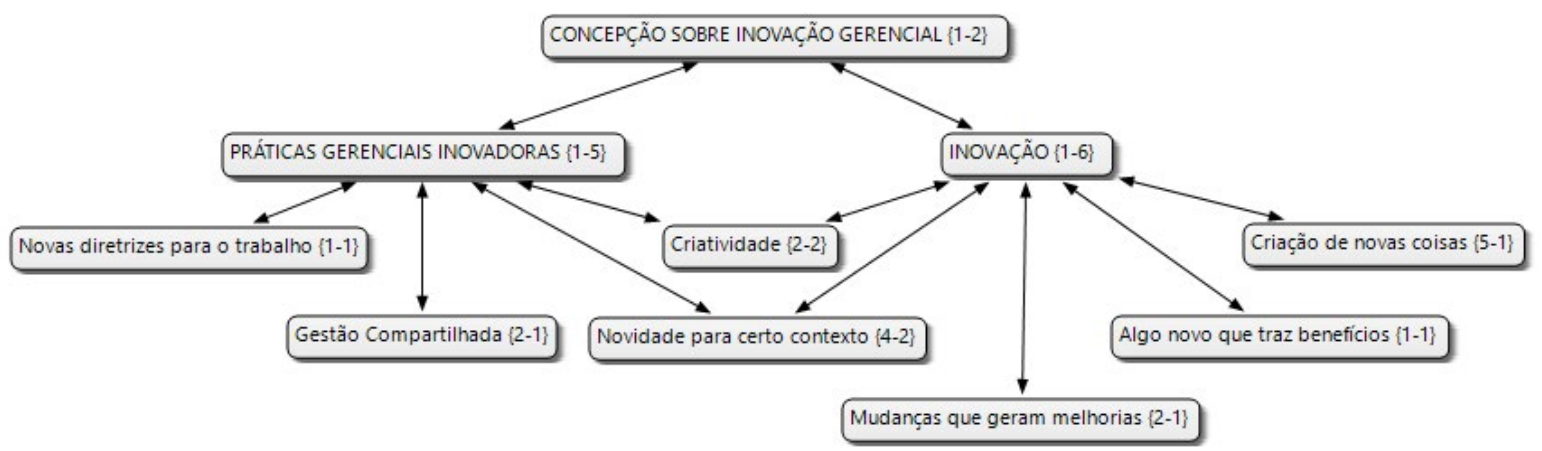

Fonte: Dados da pesquisa (2021).

A noção de inovação revelou diferentes significados para os participantes, como as ideias de inovação como criação de coisas novas e criatividade, ambas no sentido de trazer alternativas dinâmicas e proativas para a solução de problemas no contexto organizacional. Com relação ao entendimento dos gestores sobre práticas gerenciais inovadoras, surgiu no discurso de dois gestores o sentido de gestão compartilhada, em que a novidade está ligada ao estilo gerencial vivenciado atualmente, que é mais flexível, menos hierárquico e que promove um ambiente de partilha de ideias: "Eu acredito que por muitos anos se praticou a gestão muito hierárquica e talvez também não existia ambientes criativos dentro das organizações [...] Hoje, eu acredito que as pessoas já começam a pensar em ter ambientes mais criativos e proporcionar aos colaboradores oportunidades de expor ideias, de trazer alternativas, de buscar realmente a inovação, que acho que isso não aconteceu no passado" (E10).

Ao serem questionados sobre inovações implementadas por eles em sua ação gerencial, os gestores evocaram diferentes atividades e destacaram as mais inovadoras, como feedbacks constantes para suas equipes de trabalho, prestação de serviço de consultoria de Recursos Humanos para a empresa, elaboração estratégica de resultados de vendas, desenvolvimento de competências de liderança, otimização de processos organizacionais e aprimoramento de ações voltadas para o diálogo com a equipe.

$\mathrm{Na}$ segunda categoria de análise foi investigada a compreensão dos gestores acerca das competências gerenciais e sua relação com suas ações gerenciais, gerando a rede semântica representada pela Figura 2.

Sobre a competência relacionada à construção de uma base de poder, destacam-se os conteúdos relatados por seis gestores, os quais entendem o poder no sentido da autoridade que lhe é concedida por conta da sua função de líder e chefe de departamento. O E6 relata: "é um poder que eu estou na condição de gestora; eu acabo tendo informações pra poder ter um desdobramento com essas pessoas, então eu tenho um nível de responsabilidade e complexidade das atividades maior". Esse discurso está associado ao modelo de processos internos do Quinn et al. (2003), em que a ênfase da gestão é a manutenção da estabilidade das atividades gerenciais por meio de processos como a definição de sistemas de controle e hierarquia organizacional, voltado para o planejamento gerencial e o cumprimento de regras, permitindo menos abertura para o fluxo novas ideias. 
Figura 2 - Dimensão da concepção sobre competências gerenciais.

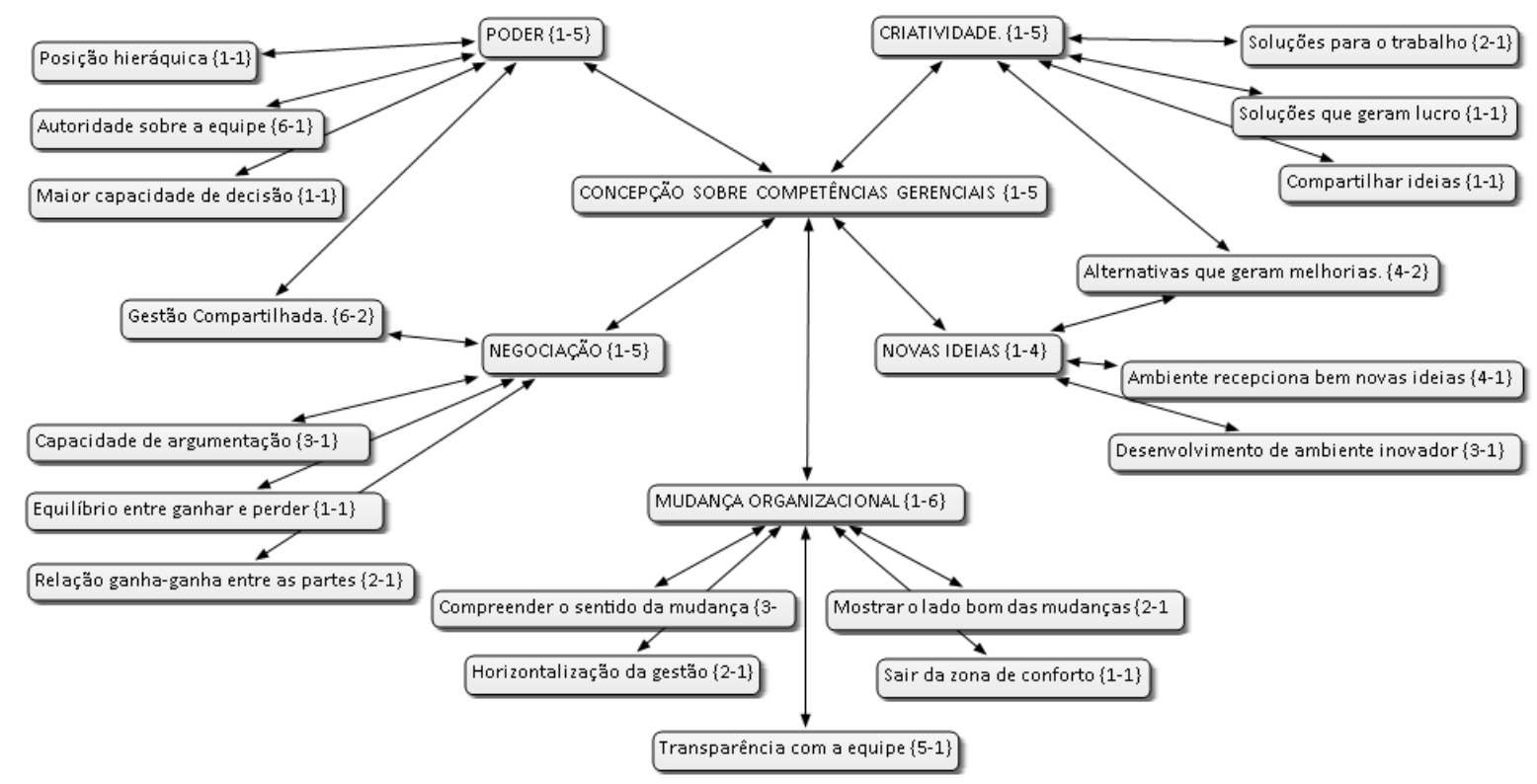

Fonte: Dados da pesquisa (2021).

No tocante à competência que envolve negociação, dois entrevistados enfatizaram a relação "ganha-ganha" entre as partes como principal referência das suas ações como negociadores. Esse perfil de negociador concorda com Haselhuhn (2015) quando esse autor argumenta que cabe ao negociador ser flexível o suficiente para permitir que o outro alcance os resultados que ele julga mais importantes para ele, ao mesmo tempo que garante resultados positivos para si mesmo. Ademais, a noção de gestão compartilhada também foi evocada como uma das maneiras de saber negociar, sendo defendida por dois gestores como uma habilidade que envolve saber persuadir, saber ouvir e construir ideias, equilibrando os interesses dos grupos. Essa noção de compartilhamento de negociação se aproxima da visão de Kelley e Bisel (2014), que defendem que, quando é desenvolvido um clima de confiança na negociação, as ideias sugeridas pelo grupo passam a ser consideradas recursos passíveis de serem explorados, gerando o compartilhamento das ideias que buscam solucionar problemas e atender aos diferentes interesses das partes.

Dos conteúdos encontrados a respeito da competência que lida com mudança organizacional, o significado mais presente no discurso dos entrevistados foi a questão da transparência para com a equipe de trabalho. Os conteúdos evocados pelos gestores representam uma das práticas de gestão de mudança organizacional evidenciada no estudo de Machado e Neiva (2017), que é a comunicação. Essa prática de transmissão das informações permite que os trabalhadores entendam as razões e o ritmo das mudanças, facilitando a aceitação e a adaptação das novas alterações nos diferentes níveis organizacionais (estratégico, tático e operacional).

A respeito da competência gerencial ligada à apresentação de novas ideias, três gestores mencionaram que o desenvolvimento de ambiente inovador configura-se como um desafio para as atividades gerenciais, sendo criado um clima que favorece tanto a apresentação como o recebimento de novas ideias. O entendimento dos gestores sobre o sucesso da apresentação de novas ideias associado ao ambiente inovador corrobora com o estudo de Scarpin e Machado (2012). Segundo esses autores, a eficiência da absorção e aplicação de inovações nas organizações está diretamente ligada às condições do ambiente organizacional e à forma como é planejado e estruturado para receber novas ideias.

Notou-se, ainda, uma semelhança entre os conteúdos evocados com relação às competências de apresentação de novas ideias e de criatividade. Ambas as competências são compreendidas pelos gestores como alternativas que geram melhorias em produtos e processos nas organizações. Esse mesmo conteúdo foi mencionado anteriormente por outros gestores ao tratarem sobre a concepção de práticas gerenciais inovadoras. Os relatos dos gestores sobre criatividade e novas ideias condizem com o que explicam Hero, Lindfors e Taatila (2017). Segundo esses autores, a criatividade é essencial para a elaboração de novas ideias, que geram inovações. Ademais, a criatividade envolve a habilidade de visionar diferentes perspectivas sobre o ambiente e gerar novas ideias para a solução de problemas organizacionais.

$\mathrm{Na}$ terceira categoria de análise investigou-se a concepção sobre o ambiente interno orientado para inovação, gerando a rede semântica representada na Figura 3. 
Figura 3 - Dimensão da concepção sobre a estrutura organizacional orientada para inovação.

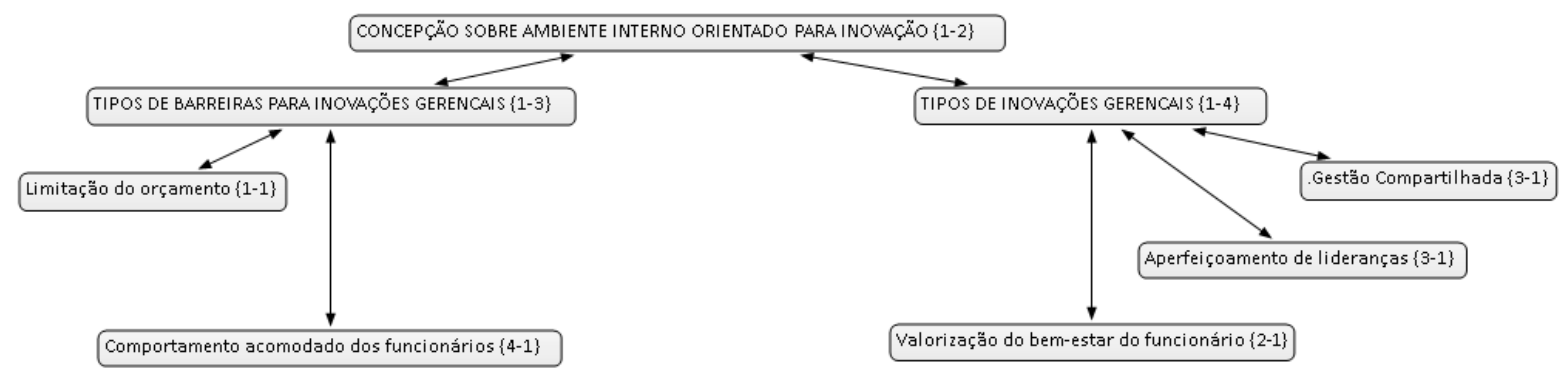

Fonte: Dados da pesquisa (2021).

Foram questionados quais tipos de inovações gerenciais são percebidas pelos gestores. Em resposta, a gestão compartilhada foi mencionada por três gestores como maior inovação gerencial. O estilo de gestão que envolve compartilhamento de ideias pode estar relacionado ao desenvolvimento de uma cultura organizacional orientada para a inovação. A cultura é uma das variáveis relevantes mencionadas por Fiates et al. (2010) na criação de um ambiente propício à inovação. A gestão compartilhada pode, então, estar ligada a uma cultura que tem como prioridade a aquisição e compatilhamento de conhecimentos, além de busca por experiências que geram aprendizagem e, consequentemente, outras inovações (NEELY; HII, 1998; SLUIS, 2004).

Quando questionados se seus superiores incentivam a inovação gerencial, todos os participantes concordaram que sim. O E5 detalha: "[...] o que eu consigo identificar é, principalmente, na parte de compartilhamento. [...] Nosso quadro de diretoria também, na minha opinião, é um quadro diferenciado porque conversa bastante, tem uma acessibilidade com eles muito grande, que com essa liberdade tem até que tomar cuidado para não fugir da hierarquização. Então a minha principal visão do quadro gerencial da empresa hoje é muito boa no sentido dessas inovações, 'tá' mais próximo dos que você lidera, tem um compartilhamento de ideias, saber ouvir".

Essa mudança no modelo de gestão vem tornando o corpo gerencial mais próximo das suas equipes, dando mais acesso ao diálogo, liberdade para sugerir novas ideias e em busca de soluções para os desafios no setor. $\mathrm{O}$ apoio da alta administração para a implementação de inovações, aproximando-se dos resultados obtidos por Parilon e Albuquerque (2010) e Vicenti e Machado (2010), quando esses autores identificaram que o suporte oferecido pelos gestores do nível estratégico e a existência de um processo decisório perticipativo promovem um ambiente interno propício à inovações.

Analisando possíveis barreiras percebidas na empresa que possam impedir uma atuação inovadora por parte dos gestores, destacou-se o conteúdo relacionado à gestão de pessoas, especificamente sobre o comportamento acomodado de alguns funcionários, assunto mencionado por quatro gestores. Sobre esse assunto, o E5 diz: "a principal barreira é a acomodação. Algumas pessoas estão acomodadas dentro da estrutura organizacional, até falo de gestão, realmente [...] Tem muita gente na zona de conforto... isso 'tá' mudando bastante, como eu falei, nosso quadro de diretoria é bem diferenciado e 'tá' mudando. Hoje, 'tá' bem melhor, mas essa parte de estar acomodado". Esse relato corrobora com o que defende Fiates et al. (2010) sobre a relevância da variável "recursos humanos" no ambiente interno: o desenvolvimento de pessoas e de suas competências colabora para o engajamento dos trabalhadores, os quais promovem a geração de novas ideias para a solução de problemas organizacionais.

A partir dos conteúdos evocados, percebe-se que a apresentação e o compartilhamento de novas ideias por meio de um modelo de gestão compartilhado é considerado pelos entrevistados o principal elemento relacionado ao fenômeno da inovação gerencial, ideia presente nas três dimensões analisadas neste estudo, como demonstra a rede semântica representada pela Figura 4 (o conteúdo "gestão compartilhada" localiza-se no centro). 
Figura 4 - "Gestão compartilhada" como conteúdo mais evocado nas entrevistas.

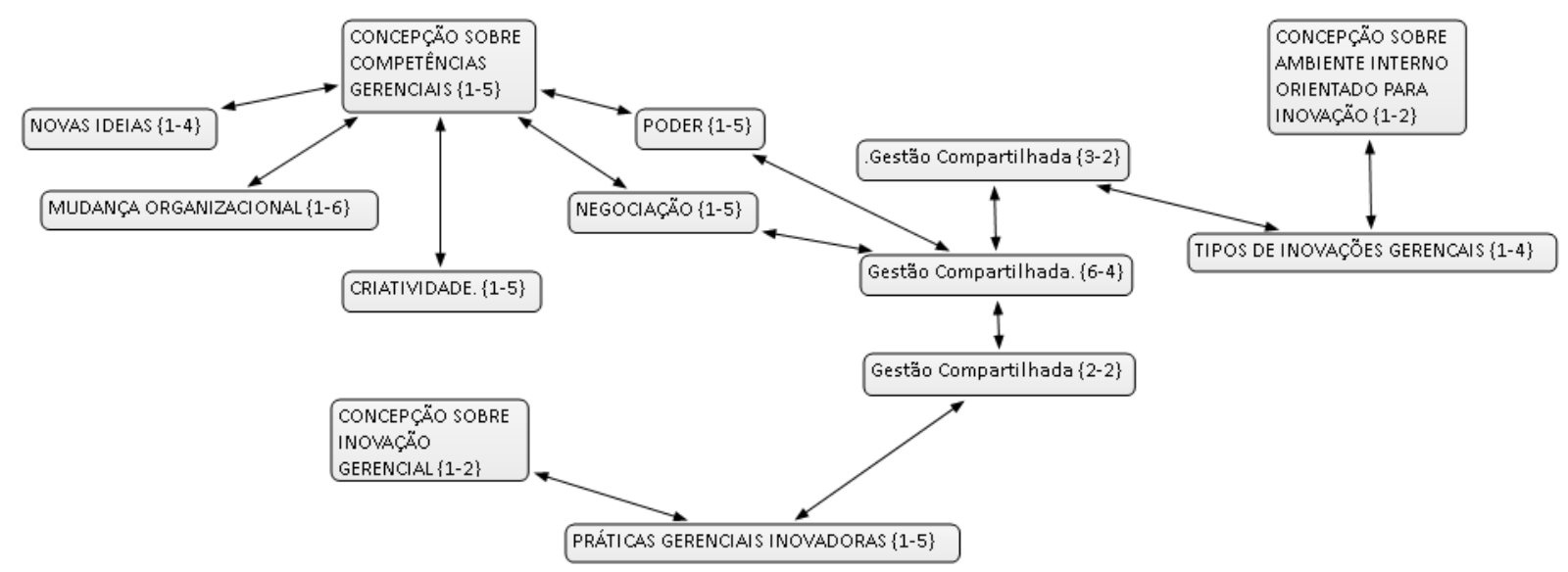

Fonte: Dados da pesquisa (2021).

A ideia da gestão compartilhada, ainda que proveniente de relatos em diferentes dimensões de análise, está presente na dinâmica organizacional e é coerente com o que versa a literatura sobre o fenômeno das inovações gerenciais. Primeiramente, o discurso dos gestores é alusivo ao que dissertam Lin e Su (2014) e Damanpour (2014) quando descrevem as inovações gerenciais como sendo a proposta de novas práticas de gestão ligadas a mudanças estruturais administrativas, de autoridade e poder, e de procedimentos organizacionais. Ademais, o desenvolvimento de competências gerenciais necessárias para ambientes com estruturas flexíveis e em constantes mudanças é possível em um modelo de gestão baseado na troca de informações e aprendizagem contínua, como prevê o modelo de sistemas abertos de Quinn et al. (2003). Por fim, a gestão compartilhada é fruto de um ambiente interno orientado para permitir a criação, desenvolvimento e implementação de novas ideias, que promovem a solução de problemas organizacionais. De acordo com o discurso dos gestores, a cultura e a estrutura organizacional, assim como os recursos humanos, são variáveis relevantes para a promoção de um ambiente interno inovador (FIATES et al., 2010).

Ao confrontar os resultados encontrados com o objeto de estudo escolhido para esta pesquisa - a indústria cimenteira, a pesquisa revelou que é possível atestar o caráter inovador singular daquela indústria. Mesmo reconhecendo que o cimento em si é um produto que não inova na sua forma e aplicação, sendo considerado um produto commodity (HAGUENAUER, 1997), foi possível verificar no discurso dos gestores que a indústria está constantemente buscando e apoiando ações inovadoras, desenvolvendo competências gerenciais voltadas para ambientes dinâmicos e competitivos, além de trabalhar para promover um ambiente interno propício à inovações.

Diante dos resultados obtidos e das redes semânticas geradas, percebe-se que a análise das informações proporcionaram a compreensão sobre o fenômeno da inovação gerencial na visão dos gestores entrevistados, a partir da sua concepção acerca do significado de inovações gerenciais e a relação destas com as competências gerenciais, além da identificação de um ambiente orientado para inovações.

\section{CONSIDERAÇÕES FINAIS}

O objetivo deste artigo foi analisar a percepção dos gestores sobre o fenômeno da inovação gerencial em uma empresa cimenteira no Brasil. A partir dos conteúdos evocados pelos entrevistados percebe-se que a apresentação e o compartilhamento de novas ideias são considerados por eles como principais elementos relacionados ao fenômeno da inovação gerencial.

A pesquisa revelou que os entrevistados compreendem inovação como criação e proposta de algo novo, capaz de trazer resultados positivos para a organização. As práticas gerenciais inovadoras, por sua vez, são vistas pelos gestores como uma maneira moderna de gerenciar pessoas e recursos organizacionais, sendo a característica que mais se destacou no relato dos gestores sobre a implementação de uma gestão compartilhada, construída por meio da participação das equipes de trabalho na busca de soluções para os problemas da empresa.

A gestão compartilhada também esteve presente nos conteúdos evocados pelos gestores quando questionados sobre sua concepção e ação gerencial acerca das competências abordadas no modelo de sistemas abertos de Quinn et al. (2003). No entendimento dos participantes, o compartilhamento de novas ideias faz parte da rotina de suas atividades gerenciais, fomentando a existência de um ambiente aberto para alternativas e soluções de problemas organizacionais. Além disso, os gestores percebem que a estrutura organizacional proporciona condições para uma atuação gerencial inovadora, embora tenham ocorrido dois relatos de alguns gestores e membros de equipes, que resistem em conduzir suas atividades de acordo com o modelo de gestão anterior da empresa: tradicional, hierárquico e centralizador de decisões. 
Destaca-se o papel da metodologia adotada para a realização deste artigo. Primeiramente, ao roteiro de entrevistas foi adicionado o uso de fichas. As fichas contribuíram para guiar e promover maior dinamicidade na coleta de informações sobre a concepção de competências gerenciais e a relação destas com a ação dos gestores. Posteriormente, a utilização do software de pesquisa qualitativa ATLAS.ti 7 foi essencial para facilitar o agrupamento dos conteúdos evocados pelos participantes nas entrevistas, gerando quatro redes semânticas que representam uma síntese gráfica do conhecimento concebido após a análise do conteúdo.

Como principal contribuição teórica foi apresentada uma análise sobre a percepção de gestores sobre o fenômeno da inovação gerencial, buscando preencher uma lacuna na literatura a respeito dessa temática aliada ao desenvolvimento de competências gerenciais. Ademais, o artigo contribui para uma melhor compreensão sobre a dinâmica inovadora da indústria cimenteira, a qual não tem tradição de inovação no produto final - mantendo características de apresentação e aplicação do cimento -, mas é amparada por diferentes tipos de inovação, como as inovações gerencais, que conferem maior competitividade e sustentabilidade econômica ao negócio.

No entanto a investigação sobre esse fenômeno não se limita aos aspectos abordados no presente artigo. Sugere-se, para futuros estudos, a realização de pesquisas acerca do fenômeno das inovações gerencais em outras empresas, com diferentes perfis de inovação (que inovam mais em seus produtos, processos ou serviços), podendo ser adotada a estratégia de pesquisa de estudos de casos múltiplos, com análise comparativa (ou QCA, Qualitative Comparative Analysis). Por fim, também propõe-se a realização de análises qualitativas e quantitativas a respeito da relação entre inovações gerenciais e variáveis específicas, como cultura organizacional, gestão do conhecimento, aprendizagem organizacional e modelo de gestão de pessoas.

\section{REFERÊNCIAS}

AIRES, R. F. F.; BRAGA, L. G.; SILVEIRA NETO, J. C.; ARAÚJO, A. G. Apoio à decisão de compra na indústria de cimentos e derivados. Revista Pretexto, Belo Horizonte, v. 17, n. 4, p. 28-46, 2016.

BARDIN, L. Análise de conteúdo. São Paulo: Edições 70, 2011.

BATTAGIN, A. Ações da indústria de cimento em direção da sustentabilidade - aspectos ambientais. In: SEMINÁRIO COPEL DE SUSTENTABILIDADE, 2010, Fortaleza. Anais [...]. Fortaleza: IBRACON, 2010.

BIRKINSHAW, J.; HAMEL, G.; MOL, M. J. Management innovation. Academy of Management Review, [S. I.], v. 33 , n. 4, p. 825-845, 2008.

CASTRO, J. M.; BASQUES, P. V. Mudança e inovação organizacional: estudo de caso em uma empresa do cluster de biotecnologia em Minas Gerais. Revista de Administração Mackenzie, São Paulo, v. 7, n 1, p. 71-95, 2006.

CARBONE, P.; BRANDÃO, H.; LEITE, J. Gestão por competências e gestão do conhecimento. Rio de Janeiro: FGV, 2008.

ČERNE, M.; KAŠE, R.; ŠKERLAVAJ, M. Non-technological innovation research: evaluating the intellectual structure and prospects of na emerging field. Scandinavian Journal of Management, [S. I.], v. 32, p. 69-85, 2016.

CHANDLER, A. D. Strategy and structure. In: FOSS, N. J. (org.). Resources firms and strategies - a reader in the resource-based perspective. Oxford: Oxford University Press, p. 40-51, 1997.

CHESBROUGH, H. W. Open innovation. Boston: Harvard Business School Press, 2003.

CHRISTENSEN, C. M. The innovator’s dilemma. Boston: Harvard Business School Press, 1997.

COUTINHO, P.; BOMTEMPO, J. V. Inovações de produto em uma empresa petroquímica. Revista Eletrônica de Administração, Porto Alegre, v. 13, n. 3, p. 24-39, 2007.

CUNHA, N. C. V.; PALMA, M. A. M.; SANTOS, S. A. D. As práticas gerenciais promovendo a capacidade de inovação: estudo de múltiplos casos. Revista ADM. MADE, Rio de janeio, v. 12, n. 3, p. 107-132, 2008.

DAMANPOUR, F. Footnotes to research on management innovation. Organization Studies, [S. I.], v. 35, n. 9 , p. 1265-1285, 2014.

DAMANPOUR, F.; ARAVIND, D. Managerial innovation: conceptions, processes, and antecedents. Management and 
Organization Review, [S. I.], v. 8, p. 423-454, 2011.

DAVILA, T.; EPSTEIN, Marc J; SHELTON, Robert. As regras da inovação. Como gerenciar, como medir e como lucrar. Porto Alegre: Bookman, 2007.

DOUGLAS, M. A.; OVERSTREET, R. E.; HAZEN, B. T. Art of the possible or fool's errand? Diffusion of large-scale management innovation. Business Horizons, [S. I.], v. 59, n. 4, p. 379-389, 2016.

DODGSON, M.; GANN, D.; PHILLIPS, N. The Oxford handbook of innovation management. Oxford: University Press, 2015.

ELENKOV, D. S.; JUDGE, W.; WRIGHT, P. Strategic leadership and executive innovation influence: an international multi-cluster comparative study. Strategic Management Journal, [S. I.], v. 26, n. 7, p. 665- 682, 2005.

FAGERBERG, J.; MOWERY, D. C.; NELSON, R. The Oxford handbook of innovation. Oxford; New York: Oxford University Press, 2006.

FIATES, G.; FIATES, J. ; SERRA, F.; FERREIRA, M. Innovation environment in small technology-based companies. Journal of Technology Management \& Innovation, [S. I.], v. 5, n. 3, p. 81-95, 2010.

FREJ, T. A.; ALENCAR, L. H. Fatores de sucesso no gerenciamento de múltiplos projetos na construção civil em Recife. Production, [S. I.], v. 20, n. 3, p. 322-334, 2010.

GIL, Antonio Carlos. Como elaborar projetos de pesquisa. 5. ed. São Paulo: Atlas, 2010.

GRAY, D. Pesquisa no mundo real. Porto Alegre: Penso, 2012.

HAGUENAUER, L. A indústria brasileira do cimento. In: GARCIA, F.; FARINA, E. M. M. Q.; ALVES, M. C. (org). Padrão de concorrência e competitividade da indústria de São Paulo: Singular, 1997. p. 135-170.

HAMEL, G. The why, what and how of management innovation. Harvard Business Review, [S. I.], p. 1-12, 2006.

HASELHUHN, M. P. Support theory in negotiation: how unpacking aspirations and alternatives can improve negotiation performance. Journal of Behavioral Decision Making, [S. I.], v. 28, p. 11-13, 2015.

HERO, L., LINDFORS, E., ; TAATILA, V. Individual innovation competence: a systematic review and future research agenda, International Journal of Higher Education, [S. I.], v. 6, n. 5, p. 103-121, 2017.

ISIDRO FILHO, A.; GUIMARÃES, T. A. Conhecimento, aprendizagem e inovação em organizações: uma proposta de articulação conceitual. Revista de Administração e Inovação, [S. I.], v. 7, n. 2, p. 127-149, 2010.

KELLEY, K. M.; BISEL, R. S. Leaders' narrative sensemaking during LMX role negotiations: Explaining how leaders make sense of who to trust and when. The Leadership Quarterly, [S. I.], v. 25, p. 433-448, 2014.

KIMBERLY, J. R. Managerial innovation. Handbook of organizational design, [S. I.], v. 1, n. p. 84-104, 1981.

KHOSRAVI, P.; NEWTON, C.; REZVANI, A. Management innovation: a systematic review and meta-analysis of past decades of research, European Management Journal, [S. I.], v. 36, n. 6, 2019.

LAM, A. Organizational innovation. In: FAGERBERG, J.; MOWERY, D.; NELSON, R. The Oxford handbook of innovations. Oxford, U. K.: Oxford University Press, 2006. p. 115-147.

LIN, H.; SU, J. A case study on adoptive management innovation in China, Journal of Organizational Change Management, [S. I.], v. 27, n. 1, p. 83-114, 2014.

LEITE, L. F.; DUTRA, L. E.; ANTUNES, A. M. S. Desenvolvimento tecnológico na indústria do petróleo: o ambiente organizacional e seus aspectos habilitadores e inibidores da inovação. Revista de Administração, [S. I.], v. 41, n. 3, p. 301-314, 2006. 
LOPES, D. P. T. Inovação gerencial na perspectiva da gestão de recursos humanos. 2017. 169f. Tese (Doutorado em Administração) - Universidade Federal de Minas Gerais, Belo Horizonte, 2017.

MACHADO, L. C. P.; NEIVA, E. R.. Práticas de gestão da mudança: impacto nas atitudes e nos resultados percebidos. Rev. Psicol., Organ. Trab., Brasília, v. 17, n. 1, p. 22-29, mar. 2017.

MARTINS, G. A.; THEÓPHILO, C. R. Metodologia da investigação científica para ciências sociais aplicadas. São Paulo: Atlas, 2009.

MEDEIROS, P. Y.; LEVY, D. C. Análise empírica dos fatores que possibilitaram entradas na indústria de cimento brasileira. Revista de Administração Mackenzie, [S. I.] v. 16, n. 6, p. 220-251, 2015.

MIGUEL, L. A. P.; TEIXEIRA, M. L. M. Valores organizacionais e criação do conhecimento organizacional inovador. Revista de Administração Contemporânea, [S. I.], v. 13, n. 1, p. 36-56, 2009.

NEELY, A.; HII, J. Innovation and business performance: a literature review. the judge institute of management studies. [S. I.]: University of Cambridge, 1998.

NICKELL, S.; NICOLITSAS, D.; PATTERSON, M. Does doing badly encourage management innovation? Oxford Bulletin of Economics and Statistics, [S. I.], v. 63, n. 1, p. 5-28, 2001.

ORGANIZAÇÃO PARAA COOPERAÇÃO E DESENVOLVIMENTO ECONÔMICO. Manual de Oslo. Diretrizes para coleta e interpretação de dados sobre inovação. 3. ed. Rio de Janeiro: FINEP, 2005.

PAROLIN, S. R. H.; ALBUQUERQUE, L. G. de. Gestão de pessoas para a criatividade em organizações inovativas. Revista Eletrônica de Administração, [S. I.], v. 16, n. 3, p. 34-52, 2010.

PINHO, A. Comprometimento, entrincheiramento e consentimento organizacionais: uma análise destes vínculos, entre gestores e trabalhadores, de diferentes organizações. 2009. Tese (Doutorado em Administração) - Universidade Federal da Bahia, Salvador, 2009.

PINHO, A. P. M.; BASTOS, A. V. B.; ROWE, D. E. O. Diferentes vínculos organizacionais: explorando concepções, fatores organizacionais antecedentes e práticas de gestão. Organizações \& Sociedade, [S. I.], v. 22, n. 75, p. 659-680, 2015.

QUINN, R. E.; THOMPSON, M.; FAERMAN, S. R.; McGRATH, M. Competências gerenciais: princípios e aplicações. Rio de Janeiro: Campus, 2003.

SCARPIN, M. R. S.; MACHADO, D. D. P. N. O impacto da cultura sobre ambiente propício ao desenvolvimento de inovações. Revista de Administração e Inovação, [S. I.], v. 12, n. 1, p. 148-173, 2015.

SCHUMPETER, J. Theorie der wirtschaftlichen Entwicklung. The Economic Journal, [S. I.], v. 23, n. 89, p. 105-106, 1913.

SINDICATO NACIONAL DA INDÚSTRIA DO CIMENTO. Relatório anual da indústria do cimento - relação de fábricas de cimento por região brasileira. Rio de Janeiro, 2014.

SLUIS, L. E. C. Designing the workplace for learning and innovation: organizational factors affecting learning and innovation. Development and Learning in Organizations, [S. I.], v. 18, n. 5, p. 10-13, 2004.

TIDD, J.; BESSANT, J.; PAVITT, K. Gestão da inovação. 3. ed. ed. Porto Alegre: Bookman, 2008.

TRIVIÑOS, A. N. S. Introdução à pesquisa em ciências sociais: a pesquisa qualitativa em educação. São Paulo: Atlas, 1987.

VACCARO, I. G.; JANSEN, J. J.; VAN DEN BOSCH, F. A.; VOLBERDA, H. W. Management innovation and leadership: the moderating role of organizational size. Journal of Management Studies, [S. I.], v. 49, p. 28-51, 2012.

VAN DE VEN, A. H.; ANGLE, H. L.; POOLE, M. S. Research on the management of innovation: the Minnesota studies. New York: Oxford University, 2000. 
VICENTI, T.; MACHADO, D.D.P.N. Ambiente de inovação em empresas de software: estudo das diferenças entre empresa-mãe e seus spin offs. Revista Eletrônica de Administração, São Paulo, v. 16, n. 1, p. 38-69, 2010.

VICK, T.; NAGANO, M.S.; SANTOS, F.C.A. Aportes da gestão da informação para a criação de conhecimento em equipes de inovação. Perspectivas em Ciência da Informação, [S. I.], v. 14, n. 2, p. 204-219, 2009.

VOLBERDA, H. W.; VAN DEN BOSCH, F. A. J.; HEIJI, C. V. Management innovation: management as fertile ground for innovation, European Management Review, [S. I.], n. 10, p. 1-15, 2013.

\section{Contato:}

Ana Paula Moreno Pinho

E-mail: ana.pinho@ufc.br

Mara Rosalia Ribeiro Silva

E-mail: mararosalia87@gmail.com

Marina Freire de Paiva Ramos Souza

E-mail: marinasouza.ce@hotmail.com

Jose Carlos Lazaro

E-mail: lazaro.ufc@gmail.com 